\title{
Balloon kyphoplasty combined with posterior pedicle screw fixation for the treatment of osteoporotic thoracolumbar burst fractures
}

\author{
Hao Yan ${ }^{1 \#}$, Ming $\mathrm{Ni}^{2 \#}$, Weifeng Zhai ${ }^{3 \#}$, Ji Guo ${ }^{3}$, Zheng Huang ${ }^{3}$, Jianpo Zhang ${ }^{3}$, Licheng Wei ${ }^{3}$ Lang Jin ${ }^{3}$, \\ Yongwei Jia
}

${ }^{1}$ Shanghai University of Traditional Chinese Medicine, Shanghai, China; ${ }^{2}$ Department of Orthopedics, Pudong New Area Peoples' Hospital Affiliated to Shanghai University of Medicine and Health Sciences, Shanghai, China; ${ }^{3}$ Department of Spine Surgery, Guanghua Hospital, Shanghai University of Traditional Chinese Medicine, Shanghai, China

Contributions: (I) Conception and design: Y Jia, Z Huang, J Zhang; (II) Administrative support: None; (III) Provision of study materials or patients: None; (IV) Collection and assembly of data: Y Jia, H Yan, M Ni, W Zhai; (V) Data analysis and interpretation: Y Jia, H Yan, M Ni, W Zhai; (VI) Manuscript writing: All authors; (VII) Final approval of manuscript: All authors.

\#These authors contributed equally to this work.

Correspondence to: Yongwei Jia. Department of Spine Surgery, Guanghua Hospital, Shanghai University of Traditional Chinese Medicine, 540 Xinhua Road, Shanghai 200052, China. Email: spinejia@163.com.

Background: Osteoporotic thoracolumbar burst fracture (TLBF) is difficult to treat due to its high rate of postoperative implant failure. This study was designed to evaluate the clinical effect of balloon kyphoplasty with polymethylmethacrylate (PMMA) and posterior pedicle screw fixation for the treatment of osteoporotic TLBF. Methods: Between February 2012 and May 2016, 24 consecutive patients with osteoporotic TLBFs were included in this study, all of whom suffered incomplete neurologic deficit. They were managed with transpedicular balloon kyphoplasty, PMMA augmentation, and posterior pedicle screw fixation. Scanning with X-ray and computed tomography (CT) were performed to evaluate the kyphotic deformity with the Cobb angle and vertebral body height loss (VBHL) of the injured vertebra. Visual analogue scale (VAS) and the Oswestry Disability Index (ODI) were adopted to assess the pain and dysfunction levels before and after the operation.

Results: All participants were followed up for an average of 18 months and those with incomplete neurologic deficit recovered completely. The Cobb angle significantly improved from a preoperative angle of $23.2^{\circ} \pm 3.6^{\circ}$ to $5.3^{\circ} \pm 2^{\circ}$ after operation and to $5.7^{\circ} \pm 2.2^{\circ}$ at the last follow up $(\mathrm{P}<0.05)$. The VBHL improved from $56.8 \% \pm 7.8 \%$ before operation to $9.1 \% \pm 1.6 \%$ after operation and to $9.7 \% \pm 1.9 \%$ at the last follow up $(\mathrm{P}<0.05)$. The visual analog scale (VAS) score decreased from $8.8 \pm 0.9$ before operation to $2.5 \pm 0.4$ after operation and to $1.4 \pm 0.4$ at the last follow up $(\mathrm{P}<0.05)$. The ODI score decreased from $88.6 \% \pm 3.5 \%$ before the operation to $32.3 \% \pm 3.7 \%$ after operation and to $17.5 \% \pm 1.8 \%$ at the last follow up $(\mathrm{P}<0.05)$.

Conclusions: Balloon kyphoplasty combined with posterior pedicle screw fixation was an effective treatment for osteoporotic TLBFs. This procedure can reconstruct 3 spinal columns using a single approach with less blood loss, short operation time, and rapid recovery. Ruptures of the posterior vertebral wall should not be a contraindication of this procedure.

Trial Registration: Chinese Clinical Trial Registry (NO.: ChiCTR1900026157).

Keywords: Osteoporosis; thoracolumbar burst fracture (TLBF); kyphoplasty; polymethylmethacrylate (PMMA); short-segment fixation

Submitted Feb 24, 2021. Accepted for publication May 10, 2021.

doi: 10.21037/apm-21-665

View this article at: http://dx.doi.org/10.21037/apm-21-665 


\section{Introduction}

Vertebral burst fracture was proposed by Holdsworth in 1970 (1). In 1983, Denis proposed his 3-column theory (2), in which burst fracture was defined as compression of the anterior and middle column, retropulsion of the fragments into the spinal canal, and vertebral burst fractures in radiological examinations. Clinical data demonstrated that almost $90 \%$ of spinal fractures occur at the thoracolumbar junction, and thoracolumbar burst fractures (TLBFs) represent about $10-20 \%$ of all spinal fractures (3). Osteoporotic TLBF is a special type of fracture and comprises approximately $13-17.1 \%$ of all osteoporotic thoracolumbar compression fractures (TLCFs) $(4,5)$. Compared with pure compression or burst fracture, osteoporotic TLBF is characterized by both osteoporosis and burst fracture. Consequently, the management of osteoporotic TLBFs is a more challenging than that of other vertebral fractures.

Posterior short-segment pedicle screw fixation has been widely accepted and used to treat TLBFs $(6,7)$. However, loss of fracture reduction and screw loosening or breakage are consistently observed in patients with osteoporosis postoperatively. The failure rate has been reported at $53-$ $77 \%(6,8)$, which could mainly be attributed to 2 factors: inadequate support for the anterior column of the injured vertebra and weak anchor strength between the bone-screw interfaces. To augment support for the anterior column, anterior instrumentation with strut autografts, mesh cages, and plates have been introduced and shown to be effective. However, the additional anterior surgery inevitably involves a further surgical invasion, more blood loss, lengthened hospital stays, and a higher morbidity (9).

The development of augmented pedicle screws, transpedicle bone grafting, vertebroplasty, and kyphoplasty with polymethylmethacrylate (PMMA) or calcium phosphate has enabled safer and sufficient anterior column reconstructions and vertebral augmentations. Both vertebroplasty and kyphoplasty are effective in managing osteoporotic vertebral fractures, and balloon kyphoplasty appears to provide a better adverse event profile than vertebroplasty (10). However, the condition of vertebral recollapse and implant failure after vertebral augmentation can potentially occur, with an incidence from $3-10 \%(11,12)$. Long-segment pedicle screw fixation with vertebroplasty augmentation in segments proximal and distal to the fractured vertebra has provided another alternative procedure to fix osteoporotic TLBFs; however, this procedure prolongs the operation time for up to 4 to 6 hours and increases blood loss (13).

The use of pedicle screws has recently been introduced to strengthen the posterior fixation of TLBFs (14). Pedicle screws in the fractured vertebra serve as mechanical crosslinks that provide 3 -point stabilization. Biomechanical studies have shown that screws placed at the level of the burst fractures could increase the stiffness of the short-segment fixation. Dick et al. (15) evaluated the biomechanical stability of 4- and 6-screw constructions on the lumbar spines of calves. Their data showed that 6-screw fixation had evident advantages over 4-screw fixation: the axial load stiffness, anti-bending capacity and torsional rigidity were $160 \%, 80 \%$, and $38 \%$, respectively, which are higher than those of 4-screw fixation. Anekstein et al. (16) also showed that the addition of intermediate screws at the level of a burst fracture significantly increases the stiffness of a short segment pedicular fixation.

In this study, 2 procedures (kyphoplasty and pedicle screw fixation) were combined to treat osteoporotic TLBFs. From February, 2012 to May, 2016, 24 patients with single burst fractures were treated with balloon kyphoplasty combined with posterior pedicle screw fixation in our hospital, and all participants had been experiencing incomplete neurologic impairments. The preliminary results were satisfactory and were reported as follows. We present the following article in accordance with the STROBE reporting checklist (available at http://dx.doi.org/10.21037/apm-21-665).

\section{Methods}

This study was a retrospective case analysis. It was completed in the Spine Surgery Department of Guanghua Hospital from February 2012 to May 2016, and approved by the medical ethical committee of the authors' institution. A total of 24 patients ( 8 males and 16 females) with osteoporotic TLBFs were included in the study. The average age was 67 years (60-81 years). The injury mechanism included falls from height $(n=18)$ and traffic accidents $(n=6)$. Physical examinations showed percussion pain of the spinous process at corresponding segments. A neurologic examination showed that all participants had incomplete neurologic deficit. Scans, including X-ray, computed tomography (CT), magnetic resonance imaging (MRI), and bone mineral density (BMD) examinations were routinely performed before the operation. The sagittal spinal curve (Cobb angle), vertebral body height 

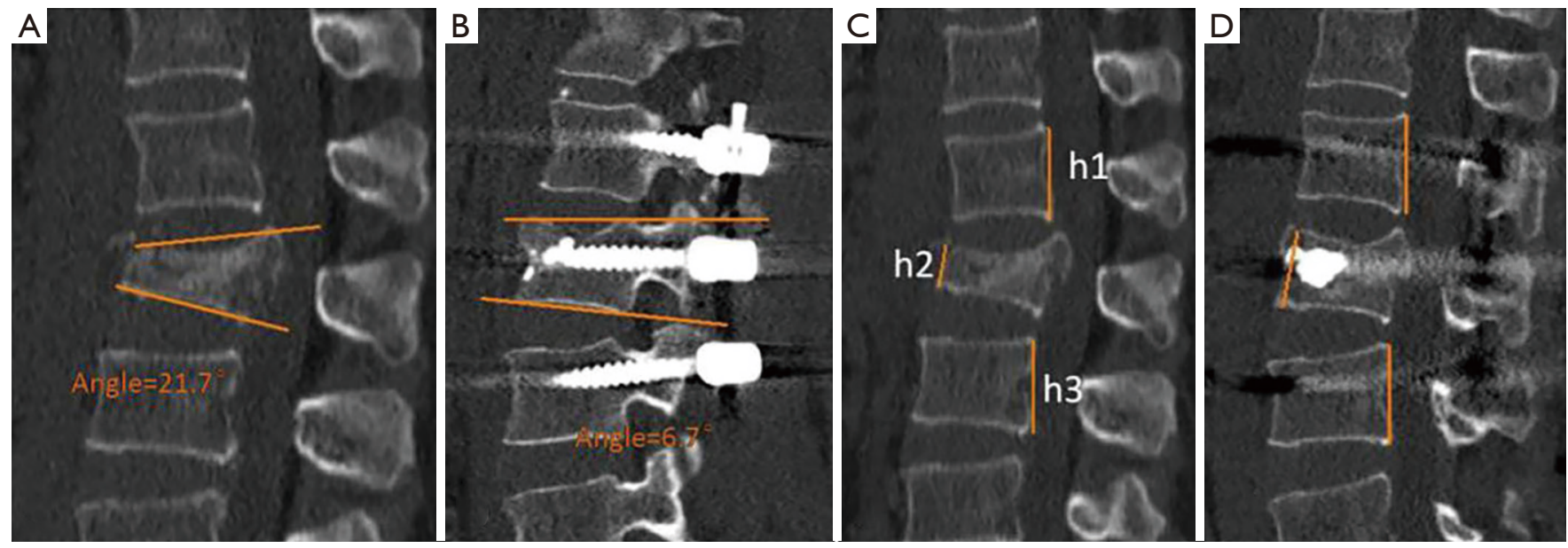

Figure $1 \mathrm{Cobb}$ angle and vertebral height loss VBHL were measured on the lateral radiographs and CT stereo-images. The Cobb angle was measured between the proximal and distal end plates of the fractured vertebrae (A,B). The VBHL was calculated with the formula $\left(1-\frac{2 * h 2}{h 1+h 3}\right) * 100 \%$, where $\mathrm{h} 1$ is the upper vertebral body height, $\mathrm{h} 2$ is the anterior vertebral body height, and h3 is the lower vertebral body height (C,D). VBHL, vertebral body height loss; CT, computed tomography.

loss (VBHL), and BMD value (T value) were measured and recorded. The Cobb angle was measured from the superior endplate to the inferior endplate of the injured vertebra. The VBHL was defined as the ratio of anterior vertebral height $(\mathrm{AVH})$ to the posterior vertebral height $(\mathrm{PVH})$ and is represented as a percentage. The PVH was calculated according to the average height of the vertebra above and below the fractured vertebra. Both the Cobb angle and VBHL were measured by the Picture Archiving and Communication Systems (PACS, Figure 1). A T value less than -2.5 was regarded as the criteria of osteoporosis. The CT scans showed a spinal canal encroachment of $30-80 \%$ (Figure 2). The distribution of the affected vertebra was T11 [1], T12 [8], L1 [9], and L2 [6]. The subtypes of the fractures were A3 $(n=19)$ and $A 4(n=5)$ according to the New AO Spine Thoracolumbar Spine Injury Classification System (17). The patients' demographic and clinical information (age, gender, injury mechanism, fracture level, fracture type, neurologic status, BMD, and interval from injury to operation) are listed in Table 1.

All procedures performed in this study involving human participants were in accordance with the Declaration of Helsinki (as revised in 2013). The study was approved by the ethics committee of Guanghua Hospital, Shanghai University of Traditional Chinese Medicine (No.: 2019-k14) and informed consent was taken from all the patients.

\section{Surgical procedure}

The surgery was performed under general anesthesia. Patients were placed in a prone position with the abdomen suspended. A posterior median approach was applied. The injured vertebra and its laminar and facet joints were exposed, and the entry points were carefully identified. A total of 4 pedicle screws (EXPEDIUM, Depuy Spine, Raynham, Massachusetts, USA) were bilaterally inserted into the adjacent vertebra above and below the fractured vertebra. For the injured vertebra, 1 screw was placed through the pedicle and the outer sleeve of cannula was implanted on the other side to prepare for kyphoplasty. The position of pedicle screws was checked with anteriorposterior (AP) and lateral fluoroscopic views. Once positioning was satisfactory, a rod of appropriate length was fixed to the pedicle screws on 1 side to temporarily preserve vertebral correction.

An expandable balloon was introduced along the pedicle cannula to the injured vertebral body, and contrast agent was injected for the radiolucent examination. The balloon was slowly inflated to restore the vertebral height under continuous fluoroscopic monitoring. The balloon was then deflated and removed, and PMMA (Tecres S.P.A, Sommacampagna, Italy) was injected until the cement diffusion reached the anterior and middle columns of the injured vertebral body. The pedicle screw was placed along 

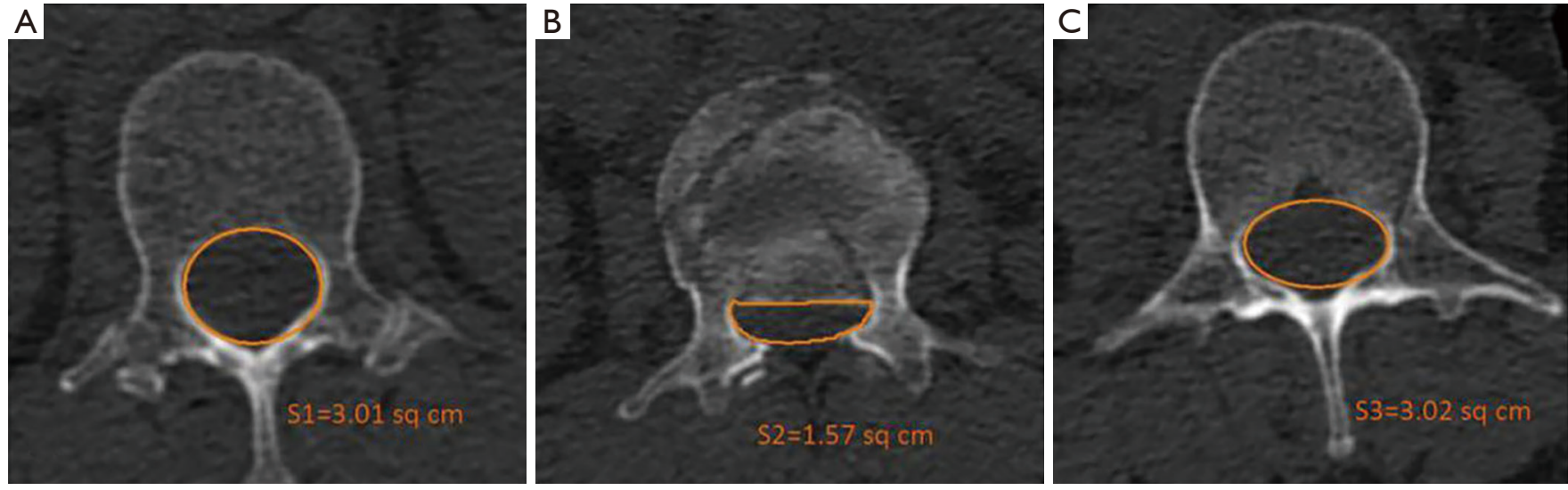

Figure 2 The calculation method for the area of spinal canal encroachment. The area of spinal canal encroachment was calculated with the formula $\left(1-\frac{2 S 2}{S 1+S 3}\right) * 100 \%$, where S1 is the spinal canal area of the upper vertebral body (A), S2 is the remaining area of the spinal canal (B), and $\mathrm{S} 3$ is the spinal canal area of the lower vertebral body $(\mathrm{C})$.

the kyphoplasty channel. A second rod was placed over the pedicle screws to achieve a rigid fixation.

Total laminectomy or hemilaminectomy was performed at the fracture level for the patients with neurological impairments. For patients with retropulsed fragments in the vertebral canal, an L-shaped retractor was used to push the fragments into vertebral column. The dura theca and nerve roots were carefully examined to confirm the absence of compression. Following irrigation of the incision, posterolateral fusion was performed using allograft bone. A total of 2 drainage tubes were routinely retained and the incision was sutured layer by layer.

\section{Postoperative management}

After the operation, antibiotic prophylaxis was conventionally used $(2 \mathrm{~g}$ Cefotiam during operation and $2 \mathrm{~g}$ twice in the following 48 hours) and the drainage tubes were removed when the volume of drainage less than $50 \mathrm{~mL} / \mathrm{d}$. The patients were encouraged to mobilize while wearing removable plastic jackets starting on the third or fourth day after the operation. Functional lumbar and lower limb exercises that could be performed in bed were advised, with the intensity gradually increased. Both X-ray and CT examinations were performed regularly $1,2,3,6,12$, and 18 months after the operation. In addition, anti-osteoporosis treatment with calcium, calcitriol, and calcitonin was suggested.

\section{Therapeutic evaluation}

A VAS was applied to evaluate participants before and after the operation and at the follow-up. Daily activities and dysfunction before and after the operation were evaluated by the Oswestry Disability Index (ODI). Bone cement leakage and recovery of spinal canal encroachment were monitored by CT.

\section{Statistical analysis}

Statistical analysis was carried out using the statistical software SPSS 17.0 (IBM Corp., Armonk, NY, USA). The parameters were expressed as mean \pm standard deviation. Continuous variables were analyzed for differences using Student's $t$-test. A P value $<0.05$ indicated a significant difference.

\section{Results}

All operations were accomplished successfully. The average operation time was $122.5 \mathrm{~min}$ (90-200 $\mathrm{min})$. The average estimated blood loss was $287.8 \mathrm{~mL}(110-550 \mathrm{~mL})$. The average amount of cement augmentation was $4 \mathrm{~mL}$ (3-5 mL).

All participants were followed-up for an average of 18 months (12-36 months) and reported considerable lumbar pain relief after the operation. The participants with incomplete neurologic deficit were completely recovered 
Table 1 Patient demographic and clinical information

\begin{tabular}{|c|c|c|c|c|c|c|c|c|}
\hline No. & Gender & Age & Injury mechanism & Fracture level & Fracture type & ASIA & $\mathrm{BMD}(\mathrm{T})$ & $\begin{array}{l}\text { Injury-operation } \\
\text { interval (days) }\end{array}$ \\
\hline 1 & $\mathrm{~F}$ & 65 & Fall & T12 & $\mathrm{A} 3$ & $\mathrm{D}$ & -2.5 & 3 \\
\hline 3 & M & 76 & Fall & T12 & A3 & $\mathrm{D}$ & -3.0 & 4 \\
\hline 6 & $M$ & 62 & Traffic accident & $\mathrm{T} 12$ & A4 & $\mathrm{D}$ & -2.5 & 2 \\
\hline 7 & $\mathrm{~F}$ & 61 & Fall & L1 & A3 & $\mathrm{D}$ & -3.0 & 4 \\
\hline 8 & $M$ & 60 & Traffic accident & L1 & A3 & $\mathrm{D}$ & -2.5 & 2 \\
\hline 12 & $\mathrm{~F}$ & 62 & Traffic accident & $\mathrm{T} 12$ & A4 & $\mathrm{C}$ & -3.0 & 2 \\
\hline 13 & M & 81 & Fall & $\mathrm{T} 11$ & A3 & $\mathrm{D}$ & -4.0 & 7 \\
\hline 14 & $\mathrm{~F}$ & 65 & Fall & L2 & A3 & $\mathrm{D}$ & -2.5 & 3 \\
\hline 15 & $\mathrm{~F}$ & 64 & Traffic accident & L1 & A3 & $\mathrm{D}$ & -2.5 & 2 \\
\hline 16 & $\mathrm{~F}$ & 67 & Fall & L2 & A3 & $\mathrm{D}$ & -3.0 & 4 \\
\hline 17 & $\mathrm{~F}$ & 66 & Traffic accident & L1 & A4 & $\mathrm{C}$ & -3.0 & 2 \\
\hline 18 & $\mathrm{~F}$ & 65 & Fall & L2 & A3 & $\mathrm{D}$ & -3.0 & 4 \\
\hline 24 & M & 70 & Fall & L1 & A3 & $\mathrm{D}$ & -3.5 & 4 \\
\hline
\end{tabular}

Injury type was classified by New AO Spine Thoracolumbar Spine Injury Classification System (17). Neurologic status was determined according to the ASIA Impairment Scale. M, male; F, female; ASIA, American Spinal Injury Association.

following surgery. No screw loosening or recollapse of the injured vertebra were observed. A solitary participant suffered an adjacent vertebral fracture 3 years after the operation, and was healed after a second kyphoplasty. The CT scan showed that 2 participants had bone cement leakage into the paravertebral tissues, but no clinical symptoms were observed. The X-rays and CTs of 1 participant treated by balloon kyphoplasty with posterior pedicle screw fixation are shown in Figure 3.

We found the preoperative Cobb angle decreased from $23.2^{\circ} \pm 3.6^{\circ}$ before the operation to $5.3^{\circ} \pm 2^{\circ}$ after the operation and to $5.7^{\circ} \pm 2.2^{\circ}$ at the last follow up $(\mathrm{P}<0.05)$. The VBHL improved from $56.8 \% \pm 7.8 \%$ before the operation to $9.1 \% \pm 1.6 \%$ after the operation and to $9.7 \% \pm 1.9 \%$ at the last follow up $(\mathrm{P}<0.05)$. The average VAS score before the operation was $8.8 \pm 0.9$ and improved to $2.5 \pm 0.4$ after the operation and to $1.4 \pm 0.4$ at the final follow up $(\mathrm{P}<0.05)$. The ODI score decreased from an average of $88.6 \% \pm 3.5 \%$ before the operation to $32.3 \% \pm 3.7 \%$ after the operation and to $17.5 \% \pm 1.8 \%$ at the last follow up $(\mathrm{P}<0.05)$. 

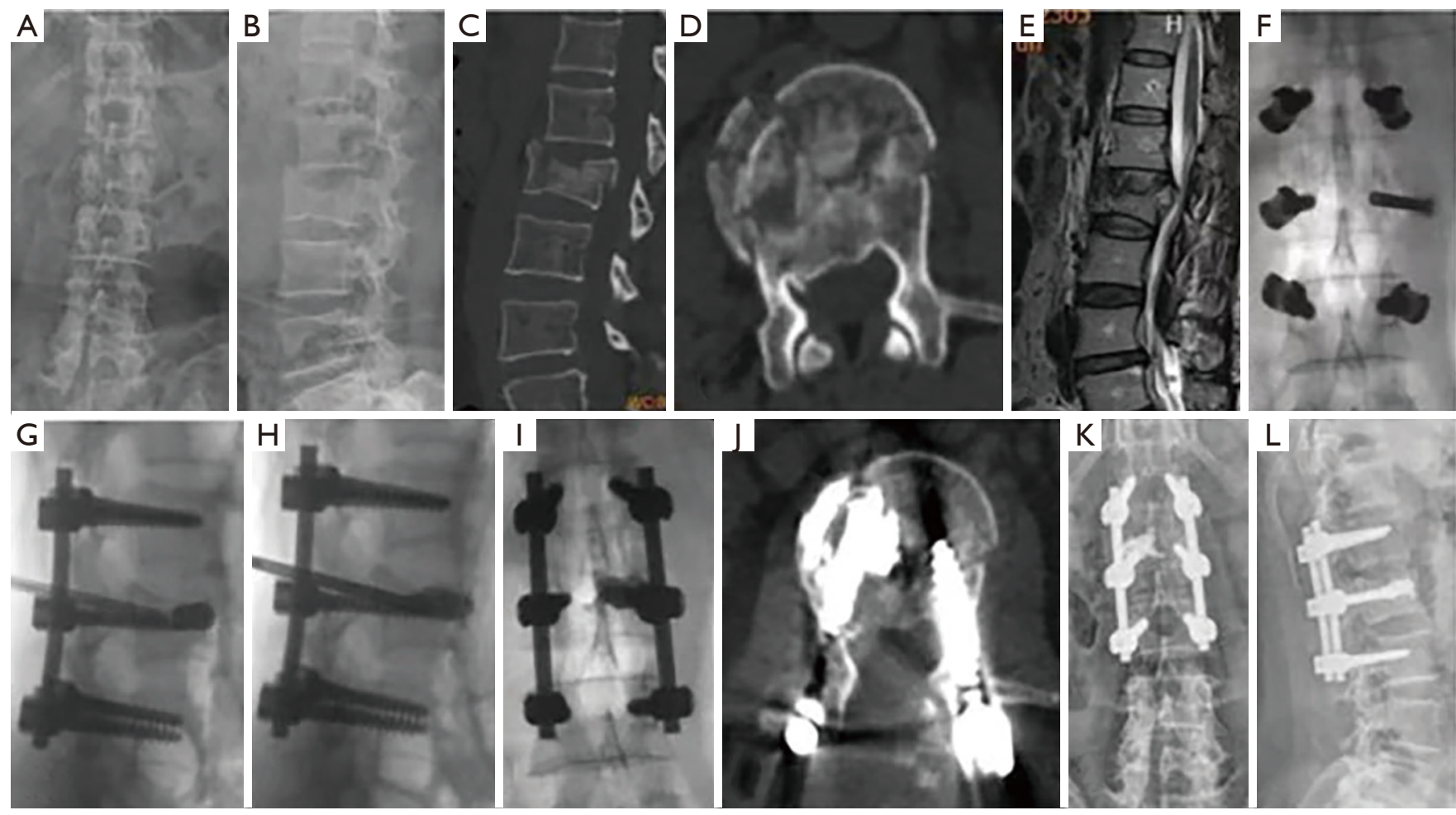

Figure 3 The X-ray and CT images of a 68-year female patient with an L2 vertebral burst fracture who underwent balloon kyphoplasty augmentation with PMMA and posterior intermediate screw fixation. X-ray (A,B) and CT images (C,D) before the operation. The preoperative MRI showing spinal canal encroached by the fragment (E). Key steps during the operation (F,G,H,I), and the CT and X-ray images at the last follow-up (J,K,L). CT, computed tomography; PMMA, polymethylmethacrylate; MRI, magnetic resonance imaging.

Detailed dataare displayed in Table 2.

\section{Discussion}

This study demonstrated that osteoporotic TLBFs in elderly patients with neurologic deficits can be effectively treated by balloon kyphoplasty combined with posterior pedicle screw fixation through a single incision. Fracture reduction and fixation were achieved using pedicle screws in fractured vertebra, and adjacent upper and lower vertebra. Reconstruction of the anterior column was performed by balloon-assisted expansion and was followed by an injection of PMMA cement. Maintenance of the vertebral middle column height and Cobb angle was observed in all participants, and no screw breakage and secondary deformity were found.

At present, the common surgical methods for thoracolumbar burst fractures include short segment posterior fixation (SSPF), short segment posterior fixation with intermediate screws at fractured level (SSPFI), long segment posterior fixation (LSPF) and combined with bone cement. However, there is no unified conclusion about which internal fixation method can obtain better fixation effect. Because of suspension effect and quadrilateral effect, simple SSPF may lead to loss of correction and loosening or fracture of internal fixation $(18,19)$. Although LSPF can obtain a more reliable fixation, it is not conducive to the postoperative recovery in the elderly due to its longer operation time and larger trauma. To avoid the above complications, SSPFI has been widely used in clinic in recent years. Biomechanical studies have verified that SSPFI can reduce screw stress, increase axial bearing capacity, antiflexion ability, anti-rotation ability of internal fixation, and improve the stability of the spine when compared to SSPF $(20,21)$. In this study, combined with balloon kyphoplasty, the immediate stability of the fixed segment after operation can be further improved without increasing the fixed segment.

Pedicle screw fixation with balloon kyphoplasty was developed after the emergence of transpedicular fixation, 
Table 2 Comparison of the kyphotic Cobb angles, VBHLs, VAS scores, and ODI scores before and after the operation and at the last follow-up

\begin{tabular}{|c|c|c|c|c|c|c|}
\hline Parameters & Preoperation & $\begin{array}{c}2 \text { days after } \\
\text { surgery }\end{array}$ & $\begin{array}{c}3 \text { months after } \\
\text { surgery }\end{array}$ & $\begin{array}{c}6 \text { months after } \\
\text { surgery }\end{array}$ & $\begin{array}{c}12 \text { months after } \\
\text { surgery }\end{array}$ & Final follow-up \\
\hline Cobb angle $\left({ }^{\circ}\right)$ & $23.2 \pm 3.6^{*}$ & $5.3 \pm 2$ & $5.4 \pm 2.2$ & $5.5 \pm 2.1$ & $5.6 \pm 2.4$ & $5.7 \pm 2.2$ \\
\hline VAS score & $8.8 \pm 0.9^{*}$ & $2.5 \pm 0.4$ & $2.2 \pm 0.5$ & $1.8 \pm 0.4$ & $1.6 \pm 0.5$ & $1.4 \pm 0.4$ \\
\hline
\end{tabular}

Compared with before surgery in the same group, * $\mathrm{P}<0.05$. VBHL, vertebral body height loss; VAS, visual analog scale; ODI, Oswestry Disability Index.

inflatable balloons, injectable PMMA, and other bone substitutes. Compared with single posterior shortsegment pedicle screw fixation, kyphoplasty could offer additional support to the anterior column, thus improving fixation stability. Mermelstein et al. (22) investigated the biomechanical stability of TLBFs reinforced by calcium phosphate cement (CPC) in a cadaveric study and showed the transpedicular vertebral body reconstruction with hydroxyapatite cement could significantly reduce the incidence of pedicle screw bending by $59 \%$ in flexion and $38 \%$ in extension. Mean initial stiffness in the flexionextension plane was increased by $40 \%$. Verlaan et al. (23) performed balloon kyphoplasty after posterior shortsegment reduction and fixation to treat traumatic burst fractures and showed that the technique was practical and effective. The postoperative radiographs and MRIs demonstrated a good fracture reduction and filling of the bone defect without unwarranted bone displacement. Similar results were also reported by Fuentes et al. $(12,24,25)$.

Despite successful applications, kyphoplasty with PMMA combined with posterior fixation has been seldom reported as treatment for osteoporotic TLBFs. In this study, we performed the procedure in patients with osteoporosis, and found the results were promising. In this series, the Cobb angle changed from $23.2^{\circ} \pm 3.6^{\circ}$ before surgery to $5.3^{\circ} \pm 2^{\circ}$ immediately after surgery. The VBHL changed from $56.8 \% \pm 7.8 \%$ to $9.1 \% \pm 1.6 \%$ after surgery. Notably, loss of correction slightly occurred during following-up, which could mainly be contributed to 3 factors: reconstruction of the anterior column by kyphoplasty, use of pedicle screws, and posterolateral fusion. Pedicle screws could provide a 3 -point fixation of the fractured segment, and significantly increase the stiffness of pedicle screw fixation. Anekstein et al. (16) compared the biomechanical stability of 4- and 6-screw constructs for unstable lumbar spine fractures and found that the addition of intermediate screws at the level of a burst fracture significantly increases the stiffness of a short segment pedicular fixation. Posterolateral fusion combined with pedicle screw fixation could provide better anterior and posterior support, lumbar lordosis, normal sagittal contour, and spinal biomechanics than fusion without screws (26).

In this study, the average duration of the operation was $122.5 \mathrm{~min}(90-200 \mathrm{~min}$ ), and the average blood loss was $287.8 \mathrm{~mL}(110-550 \mathrm{~mL})$. The average VAS score dropped significantly from $8.8 \pm 0.9$ before the operation to $2.5 \pm 0.4$ after operation and to $1.4 \pm 0.4$ at the final follow up. The ODI score dropped from an average $88.6 \% \pm 3.5 \%$ before operation to $32.3 \% \pm 3.7 \%$ after operation and to $17.5 \% \pm 1.8 \%$ at the last follow up. No implant failures were observed in this series. Our results are similar to the reports by Korovessis et al. (9), but are better than the results by Afzal et al. (20), which indicated that the mean operation times were $75 \mathrm{~min}$ with a blood loss of $350 \mathrm{~mL}$ and $142 \mathrm{~min}$ with an average $720 \mathrm{~mL}$ blood loss, respectively. All of these studies indicated that balloon kyphoplasty combined with posterior pedicle screw fixation was a preferable choice for osteoporotic TLBFs.

In the present study, PMMA rather than CPC was used to reconstruct the anterior column. A biomechanical study demonstrated that PMMA displayed similar behavior to $\mathrm{CPC}$ in human osteoporotic lumbar vertebra after prophylactic kyphoplasty (27). However, some studies have indicated that CPC is not an ideal bone substitute and has drawbacks including short freezing time, poor injectability, and early absorption (28-30). Piazzolla et al. (28) presented a case of vertebral body recollapse after kyphoplasty with CPC in a patient with L1 compression fracture. Ryu et al. (29) observed that the fractured vertebra was effectively reduced during the early postoperative time, but the recurrent progression of height loss was observed during the followup period because of the absorption of CPC. Due to the 
circumstance that all participants in this group were elderly (aged more than 60 years old), the PMMA that filled in the trabecular space could increase both the strength of screws and resistance to pullout in osteoporotic vertebra (31).

Restoration of the vertebral morphology and decompression of spinal canal are essential goals of surgical intervention for osteoporotic TLBFs. However, performing open reduction under direct visualization is unreasonable and unnecessary for all fractures. In this study, fracture reduction and canal encroachment were indirectly improved by the combination of posterior ligament distraction and the support from pedicle screws and rods. Most fractures recovered automatically after temporary instrumentation was placed on one side of the injured vertebra. Previous clinical studies have demonstrated that small fragments of bone will be absorbed and that narrow vertebra will recover spontaneously over time $(32,33)$. Thus, the small fracture fragments occupying the spinal canal could be left in situ without special maneuvers.

The key points of balloon kyphoplasty augmentation are how to inject PMMA into the target vertebra and avoid cement leakage. In this study, the procedure was performed in 2 steps. Firstly, we inflated the vertebra with a balloon, restored the vertebral height, and compressed the surrounding cancellous bone to form a relatively closed cavity in the vertebra. Second, approximately $3 \mathrm{~mL}$ PMMA was injected under continuous fluoroscopy with low pressure to fill in bone defects. The optimal puncture target is at $1 / 3$ anterior segment of the vertebra. During bone cement filling, cement diffusion at the anterior and middle columns of the injured vertebra needs to be ensured. When the bone cement diffuses over $1 / 4$ of the posterior vertebra, the injection should be carefully monitored. The ideal diffusion condition is that the bone cement nears the upper and lower endplates in the lateral view, and is located bilaterally along the midline of the vertebra in the AP view. According to the spine 3-column theory, the anterior column bears $75-80 \%$ of the axial force (34), indicating that cement diffused over the anterior $2 / 3$ of vertebra is sufficient for providing mechanical support. The injection should be stopped immediately when the bone cement is diffused evenly or leaks into the extraosseous space. Then, a pedicle screw was inserted along the cement channel to ensure that the pedicle screw could form a solid entity with the vertebra after the bone cement solidified. In this study, no looseness and breakage of the pedicle screws was observed, indicating that the procedure was safe and stable.

In this study, all participants were elderly and unwilling and intolerant to a secondary operation. However, implant removal is occasionally necessary for young patients. Technically, pedicle screw removal after bone cement reinforcement is feasible. Pare et al. (35) studied the biomechanical characters of standard and fenestrated pedicle screws augmented with PMMA in the osteoporotic spine, and found that the success rate of screw removal was $88 \%$. The authors believed that screw loosening occurs earlier at the bone-cement interface than the screw-cement interfaces. Martín et al. (36) also reported the removal of PMMA augmentation screws and reoperations were not as complicated as expected. After screw removal, the use of new screws with $1 \mathrm{~mm}$ larger diameter could provide better fixation. In this study, no complications caused by retaining the implants have yet to be observed, but long-term effects should still be followed.

The occurrence of adjacent vertebral fracture is another common complication of vertebral body augmentation with cement. The literature on balloon kyphoplasty reports a subsequent fracture rate of $12-52 \%(37,38)$. In this study, 1 participant suffered an adjacent vertebral fracture, which was healed after a second kyphoplasty. The low incidence might be related to the small sample size and short followup period or to the standard anti-osteoporosis therapy and scientific rehabilitation processes. We provide the following suggestions based on our clinical observations and experiences. First, osteoporosis is the main cause of TLCF and TLBF, so long-term anti-osteoporosis treatment is necessary. We suggest that anti-osteoporosis therapy should be continued for at least half a year. Second, appropriate rehabilitation should be performed under the protection of a brace. All participants were recommended to wear a brace for 3 months after the operation and to avoid unnecessary activities. Third, surgeons must be well-experienced with spine surgery, and carefully controlled during the procedure.

\section{Conclusions}

Balloon kyphoplasty combined with posterior pedicle screw fixation was shown to be an effective treatment for osteoporotic TLBFs. This procedure has advantages such as single approach, reconstruction of 3 spinal columns, less blood loss, short operation time, and rapid recovery. However, due to the small number of participants and short follow-up period, long term follow-up and studies of larger sample size are needed to determine the value of the proposed method. 


\section{Acknowledgments}

We are grateful to Professor Lianbo Xiao, Director of Shanghai Guanghua Hospital, and Professor Jiong Mei from the Department of Orthopedics, Shanghai Sixth People's Hospital Affiliated with the Shanghai Jiao Tong University for their help and advice.

Funding: This study was supported by the general project of Shanghai Municipal Health Bureau (201840361), key project of Changning Science \& Technology Association (CNKW 2017Z05), and project of Novel Interdisciplinary of Health System in Pudong New Area, Shanghai (PWXx2020-08).

\section{Footnote}

Reporting Checklist: The authors have completed the STROBE reporting checklist. Available at http://dx.doi. org/10.21037/apm-21-665

Data Sharing Statement: Available at http://dx.doi. org/10.21037/apm-21-665

Conflicts of Interest: All authors have completed the ICMJE uniform disclosure form (available at http://dx.doi. org/10.21037/apm-21-665). Dr. Ni reports that he received funding of Project of Novel Interdisciplinary of Health System in Pudong New Area, Shanghai (PWXx2020-08) during the past 36 months. Dr. Jia reports that he received funding of the general project of Shanghai Municipal Health Bureau (201840361) and key project of Changning Science \& Technology Association (CNKW 2017Z05). The other authors have no conflicts of interest to declare.

Ethical Statement: The authors are accountable for all aspects of the work in ensuring that questions related to the accuracy or integrity of any part of the work are appropriately investigated and resolved. The study was conducted according to the Helsinki Declaration (as revised in 2013) (Ethical Principles for Medical Research Involving Human Subjects) and was approved by the ethics committee of Guanghua Hospital, Shanghai University of Traditional Chinese Medicine (No.: 2019-k-14). All patients provided their written informed consent for the publication of their identifying photographs.

Open Access Statement: This is an Open Access article distributed in accordance with the Creative Commons
Attribution-NonCommercial-NoDerivs 4.0 International License (CC BY-NC-ND 4.0), which permits the noncommercial replication and distribution of the article with the strict proviso that no changes or edits are made and the original work is properly cited (including links to both the formal publication through the relevant DOI and the license). See: https://creativecommons.org/licenses/by-nc-nd/4.0/.

\section{References}

1. Holdsworth F. Fractures, dislocations, and fracturedislocations of the spine. J Bone Joint Surg Am 1970;52:1534-51.

2. Denis F. The three column spine and its significance in the classification of acute thoracolumbar spinal injuries. Spine (Phila Pa 1976) 1983;8:817-31.

3. Wang $\mathrm{P}, \mathrm{Hu} \mathrm{X}$. Biomechanical finite element analysis of superior endplate collapse after thoracolumbar fracture surgery. Ann Transl Med 2020;8:753.

4. Ismail AA, Cooper C, Felsenberg D, et al. Number and type of vertebral deformities: epidemiological characteristics and relation to back pain and height loss. Osteoporos Int 1999;9:206-13.

5. Shin JJ, Chin DK, Yoon YS. Percutaneous vertebroplasty for the treatment of osteoporotic burst fractures. Acta Neurochir 2009;151:141-8.

6. McLain RF, Sparling E, Benson DR. Early failure of short-segment pedicle instrumentation for thoracolumbar fractures. A preliminary report. J Bone Joint Surg Am 1993;75:162-7.

7. Dai LY, Jiang LS, Jiang SD. Posterior short-segment fixation with or without fusion for thoracolumbar burst fractures: a five to seven-year prospective randomized study. J Bone Joint Surg Am 2009;91:1033-41.

8. McCormack T, Karaikovic E, Gaines RW. The load sharing classification of spine fractures. Spine (Phila $\mathrm{Pa}$ 1976) 1994;19:1741-4.

9. Korovessis P, Baikousis A, Zacharatos S, et al. Combined anterior plus posterior stabilization versus posterior shortsegment instrumentation and fusion for mid-lumbar (L2L4) burst fractures. Spine (Phila Pa 1976) 2006;31:859-68.

10. Taylor RS, Taylor RJ, Fritzell P. Balloon kyphoplasty and vertebroplasty for vertebral compression fractures: a comparative systematic review of efficacy and safety. Spine (Phila Pa 1976) 2006;31:2747-55.

11. Cho DY, Lee WY, Sheu PC. Treatment of thoracolumbar burst fractures with polymethyl methacrylate vertebroplasty and short-segment pedicle screw fixation. 
Neurosurgery 2003;53:1354-60.

12. Fuentes S, Blondel B, Metellus P, et al. Percutaneous kyphoplasty and pedicle screw fixation for the management of thoraco-lumbar burst fractures. Eur Spine J 2010;19:1281-7.

13. Aydogan M, Ozturk C, Karatoprak O, et al. The pedicle screw fixation with vertebroplasty augmentation in the surgical treatment of the severe osteoporotic spines. J Spinal Disord Tech 2009;22:444-7.

14. Kanna RM, Shetty AP, Rajasekaran S. Posterior fixation including the fractured vertebra for severe unstable thoracolumbar fractures. Spine J 2015;15:256-64.

15. Dick JC, Jones MP, Zdeblick TA, et al. A biomechanical comparison evaluating the use of intermediate screws and cross-linkage in lumbar pedicle fixation. J Spinal Disord 1994;7:402-7.

16. Anekstein Y, Brosh T, Mirovsky Y. Intermediate screws in short segment pedicular fixation for thoracic and lumbar fractures: a biomechanical study. J Spinal Disord Tech 2007;20:72-7.

17. Vaccaro AR, Oner C, Kepler CK, et al. AO Spine Spinal Cord Injury \& Trauma Knowledge Forum. AO Spine thoracolumbar spine injury classification system: fracture description, neurological status, and key modifiers. Spine (Phila Pa 1976) 2013;38:2028-37.

18. Eno JJ, Chen L, Mitsunaga MM. Short same-segment fixation of thoracolumbar burst fractures. Hawaii J Med Public Health 2012;71:19-22.

19. Tezeren G, Kuru I. Posterior fixation of thoracolumbar burst fracture short-segment pedicle fixation versus long-segment instrumentation. J Spinal disord Tech 2005;18:485-8.

20. Li C, Zhou Y, Wang H, et al. Treatment of unstable thoracolumbar fractures through short segment pedicle screw fixation techniques using pedicle fixation at the level of the fracture: a finite element analysis. PLoS ONE 2014;9:e99156.

21. Mahar A, Kim C, Wedemeyer M, et al. Short-segment fixation of lumbar burst fractures using pedicle fixation at the level of the fracture. Spine 2007;32:1503-7.

22. Mermelstein LE, McLain RF, Yerby SA. Reinforcement of thoracolumbar burst fractures with calcium phosphate cement: a biomechanical study. Spine (Phila Pa 1976) 1998;23:664-70.

23. Verlaan JJ, Dhert W JA, Verbout AJ, et al. Balloon vertebroplasty in combination with pedicle screw instrumentation: a novel technique to treat thoracic and lumbar burst fractures. Spine (Phila Pa 1976)
2005;30:E73-9.

24. Afzal S, Akbar S, Dhar SA. Short segment pedicle screw instrumentation and augmentation vertebroplasty in lumbar burst fractures: an experience. Eur Spine J 2008;17:336-41.

25. Van Herck B, Leirs G, Van Loon J. Transpedicular bone grafting as a supplement to posterior pedicle screw instrumentation in thoracolumbar burst fractures. Acta Orthop Belg 2009;75:815-21.

26. Madan S, Boeree NR. Outcome of posterior lumbar interbody fusion versus posterolateral fusion for spondylolytic spondylolisthesis. Spine (Phila Pa 1976) 2002;27:1536-42.

27. Tomita S, Kin A, Yazu M, et al. Biomechanical evaluation of kyphoplasty and vertebroplasty with calcium phosphate cement in a simulated osteoporotic compression fracture. J Orthop Sci 2003;8:192-7.

28. Piazzolla A, De Giorgi G, Solarino G. Vertebral body recollapse without trauma after kyphoplasty with calcium phosphate cement. Musculoskelet Surg 2011;95:141-5.

29. Ryu KS, Shim JH, Heo HY, et al. Therapeutic efficacy of injectable calcium phosphate cement in osteoporotic vertebral compression fractures: prospective nonrandomized controlled study at 6-month follow-up. World Neurosurg 2010;73:408-11.

30. Chen C, Lv G, Xu B, et al. Posterior short-segment instrumentation and limited segmental decompression supplemented with vertebroplasty with calcium sulphate and intermediate screws for thoracolumbar burst fractures. Eur Spine J 2014;23:1548-57.

31. Cook SD, Salkeld SL, Stanley T, et al. Biomechanical study of pedicle screw fixation in severely osteoporotic bone. Spine J 2004;4:402-8.

32. Dai LY, Wang XY, Jiang L S. Evaluation of traumatic spinal canal stenosis in thoracolumbar burst fractures: a comparison of three methods for measuring the percent canal occlusion. Eur J Radiol 2008;67:526-30.

33. Mueller LA, Degreif J, Schmidt R, et al. Ultrasoundguided spinal fracture repositioning, ligamentotaxis, and remodeling after thoracolumbar burst fractures. Spine (Phila Pa 1976) 2006;31:E739-46.

34. Goel VK, Kong W, Han JS, et al. A combined finite element and optimization investigation of lumbar spine mechanics with and without muscles. Spine (Phila $\mathrm{Pa}$ 1976) 1993;18:1531-41.

35. Paré PE, Chappuis JL, Rampersaud R, et al. Biomechanical evaluation of a novel fenestrated pedicle screw augmented with bone cement in osteoporotic spines. Spine (Phila $\mathrm{Pa}$ 
1976) 2011;36:E1210-4.

36. Martín-Fernández M, López-Herrradón A, Piñera A R, et al. Potential risks of using cement-augmented screws for spinal fusion in patients with low bone quality. Spine J 2017;17:1192-9.

37. Lin EP, Ekholm S, Hiwatashi A, et al. Vertebroplasty cement leakage into the disc increases the risk of new fracture of adjacent vertebral body. AJNR Am J Neuroradiol 2004;25:175-180.

38. Fribourg D, Tang C, Sra P, et al. Incidence of subsequent vertebral fracture after kyphoplasty. Spine (Phila $\mathrm{Pa}$ 1976) 2004;29:2270-2276.
Cite this article as: Yan H, Ni M, Zhai W, Guo J, Huang Z, Zhang J, Wei L, Jin L, Jia Y. Balloon kyphoplasty combined with posterior pedicle screw fixation for the treatment of osteoporotic thoracolumbar burst fractures. Ann Palliat Med 2021;10(7):7514-7524. doi: 10.21037/apm-21-665 